\title{
THE NEURAL NETWORK MODEL OF INDIVIDUALS CREDIT RATING
}

\author{
Ilyas I. Ismagilov ${ }^{1}$ \\ Linar A. Molotov ${ }^{2}$ \\ Alexey S. Katasev ${ }^{3}$ \\ Dina V. Kataseva ${ }^{4}$
}

\begin{abstract}
This article solves the problem of constructing and evaluating a neural network model to determine the creditworthiness of individuals. It is noted that the most important part of the modern retail market is consumer lending. Therefore, an adequate and high-quality assessment of the creditworthiness of an individual is a key aspect of providing credit to a potential borrower. The theoretical and practical aspects of assessing the creditworthiness of individuals are considered. To solve this problem, the need for the use of intelligent modeling technologies based on neural networks is being updated. The construction of a neural network model required the receipt of initial data on
\end{abstract}

borrowers. Using correlation analysis, 14 input parameters were selected that most significantly affect the output. The training and test data samples were generated to build and evaluate the adequacy of the neural network model. Training and testing of the neural network model was carried out on the basis of the analytical platform "Deductor". Analysis of contingency tables to assess the accuracy of the neural network model in the training and test samples showed positive results. The error of the first kind on the data from the training sample was $0.45 \%$, and the error of the second kind was $1.39 \%$. Accordingly, the error of the first kind was not observed on the data from the

\footnotetext{
${ }^{11}$ Kazan Federal University.

${ }^{2}{ }^{1}$ Kazan Federal University.

${ }^{3}$ Kazan National Research Technical University named after A.N. Tupolev. e-mail: molotov.linar@mail.ru. Tel.: +79377703937.

4 Kazan National Research Technical University named after A.N. Tupolev. e-mail: molotov.linar@mail.ru. Tel.: +7 9377703937.
} 
test sample, and the error of the second kind was $2.68 \%$. The results obtained indicate a high generalizing ability and adequacy of the constructed neural network, as well as the possibility of its effective practical use as part of intelligent decision support systems for granting loans to potential borrowers.

Keywords: neural network, neural network model, borrower credit rating, modeling, data mining.

\section{Introduction}

Lending to individuals is a dynamically developing market from the segment of the Russian economy over the past decades. The most important part of the modern retail market is consumer lending [1-3]. The banking sector of Russia has not always developed evenly. A characteristic activity was servicing large corporate clients, primarily in the oil and metallurgical sectors, as well as conducting operations in the financial and stock markets.

Currently, the country's economic condition is stimulating an increase in the number of loan products issued to individuals - consumer loans [4]. One of the most common banking operations is the issuance of consumer credit. It should be emphasized that the scope of consumer credit is much wider than just the purchase of durable goods, such as cars, household appliances, etc.

The process of providing a loan to an individual consists of several stages and procedures, each of which has its own characteristics. Adequate and highquality assessment of the creditworthiness of an individual is a key aspect of providing credit to a potential borrower. A thorough analysis of the client from the standpoint of its solvency allows banks to reduce the risks of nonpayment.

In this paper, theoretical and practical aspects of assessing the creditworthiness of individuals are considered. The task of assessing the creditworthiness of individuals using intelligent modeling technologies [5, 6] is the key to success in making the right economic decisions.

An assessment of the creditworthiness of individuals is understood as an analytical procedure on the basis of which an analysis of the borrower's questionnaire is carried out to 
decide whether to grant or not to issue a loan $[7,8]$. In modern conditions, it is an integral part of the successful development of a bank's business, since the quality of an assessment of a client's creditworthiness determines the effectiveness of activities that affect loss-making or profit. In this context, the relevance of the task of assessing the creditworthiness of individuals led to the development of various areas of assessment methods, and also created the necessary basis for their easier and faster implementation. The main goal of assessing the creditworthiness of individuals is expressed in creating a full and informed image and understanding of the client using the indicators characterizing him.

\section{Methods}

To solve the problem of assessing the creditworthiness of individuals, various methods and approaches are used, among which there are $[9,10]$ :

- classical economic methods;

- data mining methods.

Classical methods for assessing financial condition include scoring [11,
351

12] and expert systems [13]. Data mining methods include statistical methods [14] and machine learning methods $[15,16]$.

Among the approaches of artificial intelligence, machine learning methods [17], in particular, neural networks [18], are of great importance for assessing the creditworthiness of individuals. The construction of neural network models for the task of assessing the creditworthiness of individuals can be a productive tool for data mining. This is due to the fact that when constructing such models, one can take into account the degree of importance and strength of influence of each potential factor. This solution is achieved by distributing weights in the model.

The construction of a neural network model for assessing the creditworthiness of individuals required the receipt of initial data on borrowers. The values of the following set of parameters were used as initial data:

- age;

- marital status;

- amount of children;

- the number of years of residence in the region;

- education;

- social status; 
- income (confirmed);

- the social status of the spouse

$(\mathrm{s})$

- work experience, years;

- credit amount;

- purpose of the loan;

- interest rate, \%;

- loan term, months;

- availability of real estate;

- market value of real estate;

- the presence of a personal car;

- market value of the car;

- the availability of loans in

other banks;

- monthly payment.
In addition to the input data for the construction of a neural network model, output data are also necessary that determine the value of the node of the output network layer - approval of the application.

To assess the correlation dependence of the input parameters and the output value, we used the "Processing Wizard" tool - "Correlation Analysis", which is part of the Deductor analytical platform [19]. Correlation analysis was performed using the Pearson correlation coefficient [20]. Table 1 presents the results of the analysis.

Table 1 - The results of correlation analysis

\begin{tabular}{|l|c|}
\hline \multicolumn{1}{|c|}{ Input fields } & $\begin{array}{c}\text { Correlation coefficient } \\
\text { with output field }\end{array}$ \\
\hline Age & $-0,132$ \\
\hline Family status & 0,02 \\
\hline Amount of children & 0,04 \\
\hline Number of years of residence in the region & $-0,111$ \\
\hline Education & $-0,014$ \\
\hline Social status & 0,3 \\
\hline Revenue (Verified) & 0,629 \\
\hline Spouse's Social Status & 0,039 \\
\hline Work experience, years & $-0,132$ \\
\hline
\end{tabular}




\begin{tabular}{|l|c|}
\hline Credit amount & $-0,323$ \\
\hline Purpose of the loan & $-0,261$ \\
\hline Loan term, months & $-0,232$ \\
\hline Property Availability & $-0,1$ \\
\hline Market value of real estate & $-0,039$ \\
\hline The presence of a personal car & $-0,022$ \\
\hline Car market value & $-0,019$ \\
\hline Availability of loans in other banks & $-0,13$ \\
\hline Monthly payment & $-0,329$ \\
\hline
\end{tabular}

Correlation analysis showed that a number of parameters (such as "Marital status", "Education", "Presence of a personal car" and "Market value of a car") were insignificant, since they only slightly affect the output. Therefore, these parameters were excluded from the analysis when constructing a neural network model.

The final step in preparing data for analysis and building a neural network model is the formation of a training and test sample. Out of 1074 records of source data, about $80 \%$ of records for training a neural network were randomly selected. The remaining $20 \%$ were test data samples. It should be noted that training and testing of the neural network model was carried out on the basis of the Deductor analytical platform.

\section{Results And Discussion}

When training a neural network, results were obtained that can be represented in the form of the following contingency table (see table. 2).

Table 2 - The results of training the neural network

\begin{tabular}{|c|c|c|c|}
\hline & \multicolumn{3}{|c|}{ Categories } \\
\hline Fact & False & True & Total \\
\hline False & 446 & 2 & 448 \\
\hline
\end{tabular}




\begin{tabular}{|c|c|c|c|}
\hline True & 5 & 355 & 360 \\
\hline Total & 451 & 357 & 808 \\
\hline
\end{tabular}

The table shows only those values that were obtained in accordance with previously defined criteria, i.e. whether the application was approved or not. As can be seen from the table, the neural network classified out of 448 rejected applications 2 approved, and out of 360 approved applications 5 applications rejection model. Consequently, a mistake of the first kind (refusal to extradite heirs to a trustworthy borrower) is $1.39 \%$ (5 out of 360 cases).
The process of training a neural network model in a training sample is an assessment of the creditworthiness of individuals. If you do not assess the adequacy of models based on real data, then such a design will not make sense. To assess the adequacy of the constructed neural network model, test data can be used. Table 3 presents the results of testing the neural network.

Table 3 - The results of testing the neural network

\begin{tabular}{|c|c|c|c|}
\hline & \multicolumn{3}{|c|}{ Categories } \\
\hline Fact & False & True & Total \\
\hline False & 154 & 0 & 154 \\
\hline True & 3 & 109 & 112 \\
\hline Total & 157 & 109 & 266 \\
\hline
\end{tabular}

As can be seen from the table, when testing a neural network, only 3 errors of the second kind were received, when the loan was not approved by a potentially trustworthy borrower. It should be noted that errors of the first kind are not observed, i.e. loans are not issued to unreliable customers. At the same time, $2.68 \%$ of errors of the second kind are observed (3 out of 112 cases). In general, this indicates a high generalizing ability of the constructed neural network and the possibility of its 
effective practical use in intelligent systems of consumer lending.

\section{Summary}

The constructed neural network model is a perceptron type neural network with one hidden layer [21], including 18 neurons. Network training was performed using the back propagation method of error [22]. In the training set, the neural network erroneously classified 7 applications: 2 applications were approved out of 448 rejected, 5 applications were rejected out of 360 approved. If you look from a business point of view, it is better to reject approved applications, having lost interest on loans issued, than to approve consumer loans to unreliable customers and lose credit loans. Therefore, the results of neural network modeling can be considered satisfactory.

\section{Conclusions}

Thus, the work solved the problem of constructing an effective neural network model for assessing the creditworthiness of individuals. The results of evaluating the accuracy of the model showed its effectiveness and the possibility of practical use as part of intelligent decision support systems for granting loans to potential borrowers.

\section{Acknowledgements}

The work is performed according to the Russian Government Program of Competitive Growth of Kazan Federal University. This work was supported by the Russian Federation Ministry of Education and Science, project № 8.6141.2017/8.9.

\section{Bibliography}

Wang H., Zhong J., Zhang D., Zou X. A new classification algorithm for the bank customer credit rating // 9th International Conference on Advanced Computational Intelligence, ICACI 2017. - P. 143-148.

Abedini M., Ahmadzadeh F., Noorossana R. Customer credit scoring using a hybrid data mining approach // Kybernetes. - 2016. - No. 45(10). - P. 1576-1588.

Yi G., Lei H., Ziqiang L. Port customer credit risk prediction based on internal and external information fusion // Open Cybernetics and Systemics Journal. 2015. - No. 9(1). - P. 1323-1328. 
Li Y.-B., Zhang J.-P. Approach to multiple attribute decision making with hesitant triangular fuzzy information and their application to customer credit risk assessment // Journal of Intelligent and Fuzzy Systems. - 2014. - No. 26(6). - P. 2853-2860.

Katasev A.S., Kataseva D.V., Emaletdinova L.Yu. Neuro-fuzzy model of complex objects approximation with discrete output // Proceedings of 2nd International Conference on Industrial Engineering, Applications and Manufacturing, ICIEAM 2016.

Li B., Chai X., Zhang L., Lin T., Liu Y. Preliminary Study of Modeling and Simulation Technology Oriented to Neotype Artificial Intelligent Systems // Journal of System Simulation. - 2018. No. 30(2). - P. 349-362.

Das I., Roy S., Chatterjee A., Sen S. A data warehouse based schema design on decision-making in loan disbursement for Indian advance sector // Advances in Intelligent Systems and Computing. 2019. - No. 813. - P. 603-614.
Tronnberg C.-C., Hemlin S. Lending decision making in banks: A critical incident study of loan officers // European Management Journal. - 2014. - No. 32(2). - P. 362-372.

Hashemi Taba, N., Mahfoozi Mousavi S.K., Khatavakhotan A.S. A novel algorithm developed with integrated metrics for dynamic and smart credit rating of bank customers // Lecture Notes in Electrical Engineering. - 2019. - No. 480. - P. 787-799.

Jadhav S., He H., Jenkins K. Information gain directed genetic algorithm wrapper feature selection for credit rating // Applied Soft Computing Journal. 2018. - No. 69. - P. 541-553.

Ferreira F.A.F., Spahr R.W., Gavancha I.F.M.D., Cipi A. Readjusting trade-offs among criteria in internal ratings of credit-scoring: An empirical essay of risk analysis in mortgage loans // Journal of Business Economics and Management. - 2013. - No. 14(4). - P. 715-740.

Grunert M.L., Raker J.R., Murphy K.L., Holme T.A. Polytomous versus 
dichotomous scoring on multiple-choice examinations: Development of a rubric for rating partial credit // Journal of Chemical Education. - 2013. - No. 90(10). - P. 1310-1315.

Menekay M., MaAitah M.K.S. Applying expert system for bank credit authorization using fuzzy tools // ACM International Conference Proceeding Series. - 2017. - P. 258-261.

Ajili I., Ramezanpanah Z., Mallem M., Didier J.-Y. Expressive motions recognition and analysis with learning and statistical methods // Multimedia Tools and Applications. - 2019. - No. 8(12). - P. 16575-16600.

Ismagilov I.I., Khasanova S.F., Katasev A.S., Kataseva D.V. Neural network method of dynamic biometrics for detecting the substitution of computer // Journal of Advanced Research in Dynamical and Control Systems. - 2018. - No. 10(10 Special Issue). - P. 17231728.

Emaletdinova, L.Y., Matveev, I.V., Kabirova, A.N. Method of designing a neural controller for the automatic lateral control of unmanned aerial vehicles // Russian Aeronautics. - 2017. - No. 60(3). - P. 365-373.

Sivasankar E., Selvi C., Mala C. A study of dimensionality reduction techniques with machine learning methods for credit risk prediction // Advances in Intelligent Systems and Computing. - 2017. - No. 556. - P. 65-76.

Mustafin A.N., Katasev A.S., Akhmetvaleev A.M., Petrosyants D.G. Using models of collective neural networks for classification of the input data applying simple voting // Journal of Social Sciences Research. - 2018. Special Issue 5. - P. 333-339.

Nagy Z., Soper D.E. Jets and threshold summation in Deductor // Physical Review D. - 2018. - No. 98(1), 014035.

Saidi R., Bouaguel W., Essoussi N. Hybrid feature selection method based on the genetic algorithm and Pearson correlation coefficient // Studies in Computational Intelligence. - 2019. No. 801. - P. 3-24. 
Prom N.A., Litvinova E.A., Shokhnekh

A.V., Yovanovich T.G., Lomakin N.I.

Perseptron for assessing the students'

task performance in learning a foreign

language according to the competencies using bi data // IOP Conference Series: Materials Science and Engineering. 2019. - No. 483(1), 012048.

Bhardwaj S., Verma V. Improved Kmeans clustering algorithm using back propagation method // International Journal of Control Theory and Applications. - 2016. - No.

9(Specialissue11). - P. 5169-5180 